\title{
ELASTICIDADE DO SOLO EM FUNÇÃO DA UMIDADE E DO TEOR DE CARBONO ORGÂNICO ${ }^{(1)}$
}

\author{
João Alfredo Braida ${ }^{(2)}$, Jose Miguel Reichert ${ }^{(3)}$, Dalvan Jose \\ Reinert $^{(3)}$ \& Letícia Sequinatto ${ }^{(4)}$
}

\begin{abstract}
RESUMO
O acúmulo de carbono orgânico (CO) observado em solos sob sistema de semeadura direta pode resultar em aumento de sua elasticidade, levando a maior resistência à compactação. Este estudo foi realizado para avaliar o efeito da umidade e do enriquecimento de $\mathrm{CO}$ sobre a elasticidade de dois solos, sendo um Nitossolo Vermelho distrófico latossólico e um Argissolo Vermelho-Amarelo distrófico arênico. Amostras superficiais de solo, coletadas no Argissolo e no Nitossolo, com variação significativa do teor de $\mathrm{CO}$, foram equilibradas em quatro diferentes tensões de água e, então, submetidas a carregamentos e descarregamentos em uma prensa de compressão uniaxial, determinando-se o coeficiente de descompressão (Cd), o índice de recuperação do índice de vazios (Ir) e a redução da densidade (Re), após remoção das cargas aplicadas. Os resultados demonstram que o Ir variou de 11,4 a 16,4 \% no Nitossolo e de 14 a 23,4 \% no Argissolo, dependendo da tensão de água e do teor de $\mathrm{CO}$ da amostra. O teor de $\mathrm{CO}$ das amostras afetou significativamente o $\mathrm{Cd}$ e, conseqüentemente, a Re após a retirada das cargas. A Re média observada variou de 0,023 a $0,059 \mathrm{Mg} \mathrm{m}^{-3}$ e de 0,018 a $0,078 \mathrm{Mg} \mathrm{m}^{-3}$, respectivamente para o Argissolo e o Nitossolo. A elasticidade do solo é sensivelmente afetada pela variação no teor de água e de $\mathrm{CO}$.
\end{abstract}

Termos de indexação: matéria orgânica do solo, mecânica do solo, física do solo, compactação do solo, compressibilidade do solo, semeadura direta.

\footnotetext{
${ }^{(1)}$ Parte da Tese de Doutorado apresentada pelo primeiro autor ao Programa de Pós-Graduação em Ciência do Solo da Universidade Federal de Santa Maria - UFSM. Financiado parcialmente por CAPES, CNPq e FAPERGS. Recebido para publicação em fevereiro de 2007 e aprovado em dezembro de 2007.

(2) Professor Adjunto. Universidade Tecnológica Federal do Paraná - UTFPR. Campus Pato Branco, Caixa Postal 571, CEP 85501970 Pato Branco (PR). E-mail: braida@utfpr.edu.br

(3) Professor Titular, Departamento de Solos. Universidade Federal de Santa Maria - UFSM. Campus Universitário, CEP 97105 900 Santa Maria (RS). E-mail: reichert@smail.ufsm.br, dalvan@ccr.ufsm.br

(4) Mestrando do Departamento de Solos, UFSM. E-mail leti@mail.ufsm.br
} 


\title{
SUMMARY: SOIL ELASTICITY AS AFFECTED BY WATER AND ORGANIC CARBONCONTENT
}

\begin{abstract}
The organic carbon accumulation observed in soils under no-till system can increase the soil elasticity, resulting in a higher resistance to soil compaction. This study was carried out to evaluate the effects of water content and soil organic carbon (SOC) enrichment on soil elasticity. Samples of a Hapludalf and a Typic Hapludox in southern Brazil, both with a significant variation in SOC content, were equilibrated at four different water tensions, and then loaded and unloaded on a uniaxial apparatus. The decompression coefficient (Cd), the recovery index (Ir) of the void ratio and the density rebound (Re) after load removal were determined. Results demonstrate that Ir varied from 11.4 to $16.4 \%$ in the Hapludox and from 14 to $23.4 \%$ in the Hapludalf, depending on the water tension and $S O C$ content. The SOC content affected Cd significantly and, consequently, the rebound after load removal. The observed mean rebound varied from 0.023 to $0.059 \mathrm{Mg} \mathrm{m}^{-3}$ and from 0.018 to $0.078 \mathrm{Mg} \mathrm{m}^{-3}$, respectively, for the Hapludalf and the Hapludox. Soil elasticity is affected by variations in the water and SOC content.
\end{abstract}

Index terms: no-till, soil organic matter, soil compaction, soil compressibility, soil mechanics, soil physics.

\section{INTRODUÇÃO}

O sistema de semeadura direta possui propriedades que podem ser maximizadas com vistas a reduzir a compactação do solo e suas conseqüências. Dentre estas, destaca-se a contínua adição superficial de resíduos orgânicos, mantendo o solo coberto e enriquecendo a camada superficial com matéria orgânica (MOS). Os materiais orgânicos podem atuar de duas formas na atenuação do processo de compactação ou seus efeitos. Quando na superfície do solo, dissipam parte da pressão exercida pelas rodas das máquinas e, ou, patas de animais (Silva et al., 2000; Braida et al., 2006) e, quando incorporados à MOS, aumentam sua elasticidade e resistência à compactação, bem como os limites de umidade em que ele pode ser trabalhado mecanicamente (Soane, 1990; Braida et al., 2006).

A elasticidade do solo é dependente de dois fatores: elasticidade do material que compõe o solo (Soane, 1990); e bolhas de ar, aprisionadas e comprimidas dentro do solo durante a aplicação de uma carga, que, após a descarga, se expandem, deslocando o solo (Hillel, 1998; Perdok et al., 2002). A elasticidade do material que compõe o solo dependerá de sua natureza, orgânica ou mineral, do tamanho das partículas, do estado de decomposição do material orgânico e da mineralogia da fração mineral (Baver et al., 1972; Stone \& Larson, 1980; Soane, 1990). Além disso, O'Sullivan \& Robertson (1996) e Kirby \& O'Sullivan (1997) observaram que a inclinação da reta de descompressão varia com a umidade do solo.

A MOS, além de possuir elevado número de cargas superficiais, especialmente na faixa de $\mathrm{pH}$ encontrada nos solos, é considerada flexível e elástica, tendo grande capacidade de recuperar a forma inicial após a remoção de uma carga aplicada sobre ela (Soane, 1990). Essas características permitiriam que partículas orgânicas que estivessem ligando partículas minerais no solo fossem deformadas quando as partículas minerais forem deslocadas umas em relação às outras, por efeito da aplicação de uma carga. Ao cessar a aplicação da carga, as partículas orgânicas tenderiam a retornar à forma original, deslocando consigo as partículas minerais, resultando em expansão do solo após o descarregamento.

Na compressão de solo não-saturado, uma parte do ar fica aprisionada no seu interior, com formação de bolhas de ar comprimido. $\mathrm{O}$ aprisionamento de bolhas de ar dependerá da carga aplicada e do tempo de sua aplicação, da umidade do solo, do volume de poros e das características do espaço poroso (Perdok et al., 2002), havendo, para um dado solo, um teor de umidade em que o aprisionamento de bolhas é maior, gerando elasticidade maior.

Estudos sobre elasticidade do solo têm demonstrado que os valores encontrados não são muito expressivos (Stone \& Larson, 1980; McBride \& Watson, 1990; Perdock et al., 2002; Silva \& Cabeda, 2005) e, assim, normalmente ela não é considerada em modelos que descrevem a deformação do solo em função de cargas aplicadas em sua superfície. Entretanto, especialmente com o advento do sistema de semeadura direta, não raras vezes se tem utilizado a elasticidade do solo como umas das possíveis justificativas para a maior resistência à compactação dos solos manejados sob esse sistema. Vincula-se, ainda, a elasticidade ao aumento do teor de MOS, geralmente observado na camada superficial no sistema de semeadura direta.

Considerando que o acúmulo de MOS geralmente está associado a aumento da água retida no solo (Scheinost et al., 1997; Carvalho et al., 1999; 
Tormasella et al., 2000), ter-se-iam dois efeitos que explicariam maior elasticidade nos solos enriquecidos com matéria orgânica: elasticidade da própria matéria orgânica, que é mais elástica que as partículas minerais; e o aumento da probabilidade do confinamento de bolhas de ar, uma vez que há aumento da água retida no solo. Assim, o efeito produzido pela grande elasticidade do material orgânico seria potencializado pelo maior aprisionamento de bolhas de ar dentro da amostra enriquecida por esses materiais.

Este estudo foi realizado para avaliar o efeito do teor de água e do enriquecimento de CO sobre a elasticidade de dois solos: um Argissolo VermelhoAmarelo distrófico arênico e um Nitossolo Vermelho distrófico.

\section{MATERIAL E MÉTODOS}

O estudo foi realizado com amostras superficiais de solo (0 a 0,02 $\mathrm{m}$ de profundidade) coletadas em dois solos, sendo um Argissolo Vermelho-Amarelo distrófico arênico de textura franco arenosa e um Nitossolo Vermelho distrófico latossólico de textura argilosa (Quadro 1).

Foram montados dois experimentos de laboratório, com delineamento completamente casualizado, cujos tratamentos constituíram-se de quatro níveis de umidade do solo. Os níveis de umidade foram obtidos a partir da saturação das amostras com água e, depois, submetendo-as a tensões de $6 \mathrm{kPa}$ na mesa de tensão; 100 e $500 \mathrm{kPa}$ em placas cerâmicas; e > $500 \mathrm{kPa}$, secando-as ao ar. Foram usadas 15 e 27 repetições, respectivamente para o Argissolo e o Nitossolo.

O Nitossolo foi amostrado em um experimento localizado na Estação Experimental de Campos Novos, da Empresa de Pesquisa Agropecuária e Extensão
Rural de Santa Catarina - EPAGRI, no município de Campos Novos, SC, no qual eram avaliados sistemas de manejo de solo e de resíduos culturais e insumos orgânicos (Veiga et al., 2007). A coleta ocorreu em dezembro de 2001, durante o oitavo cultivo de verão no experimento. Foram escolhidas parcelas com base no teor de $\mathrm{CO}$ determinado previamente na camada de 0 a $0,05 \mathrm{~m}$ de profundidade, em parcelas correspondentes às seguintes situações: (1) semeadura direta (SD) com adubação química; (2) SD com aplicação de cama de aviário; (3) preparo convencional (PC) com adubação química; (4) PC com aplicação de cama de aviário; (5) PC após a remoção dos resíduos culturais, com adubação química; (6) PC após a remoção dos resíduos culturais, com aplicação de cama de aviário; (7) PC após a queima dos resíduos culturais, com adubação química; e (8) PC após a queima dos resíduos culturais, com aplicação de cama de aviário.

No Argissolo, coletaram-se amostras em um experimento conduzido na Área Experimental do Departamento de Solos da Universidade Federal de Santa Maria - UFSM, no município de Santa Maria, $\mathrm{RS}$, no qual eram avaliadas combinações de doses de esterco líquido de suínos e plantas de cobertura no sistema de semeadura direta (Aita et al., 2006). As amostras foram coletadas em novembro de 2002, antes da semeadura do quinto cultivo de verão no experimento, buscando-se ampla variação no teor de CO. Coletaram-se amostras nas seguintes situações: (a) parcela de aveia sem adição de esterco líquido de suíno; (b) parcela de aveia $+80 \mathrm{~m}^{3} \mathrm{ha}^{-1}$ de esterco líquido de suíno; (c) parcela de aveia + ervilhaca + $40 \mathrm{~m}^{3} \mathrm{ha}^{-1}$ de esterco líquido de suíno; (d) parcela de aveia + ervilhaca $+80 \mathrm{~m}^{3} \mathrm{ha}^{-1}$ de esterco líquido de suíno; e (e) área em pousio ao lado do experimento.

A elasticidade do solo foi avaliada em amostras com estrutura preservada, coletadas em anéis metálicos com 0,02 $\mathrm{m}$ de altura e 0,055 $\mathrm{m}$ de diâmetro. As amostras foram submetidas ao ensaio de adensamento

Quadro 1. Granulometria, densidade de partículas, densidade do solo e teor de carbono orgânico da camada superficial $(0,00$ a $0,05 \mathrm{~m})$ de um Argissolo Vermelho-Amarelo distrófico arênico e de um Nitossolo Vermelho distrófico latossólico

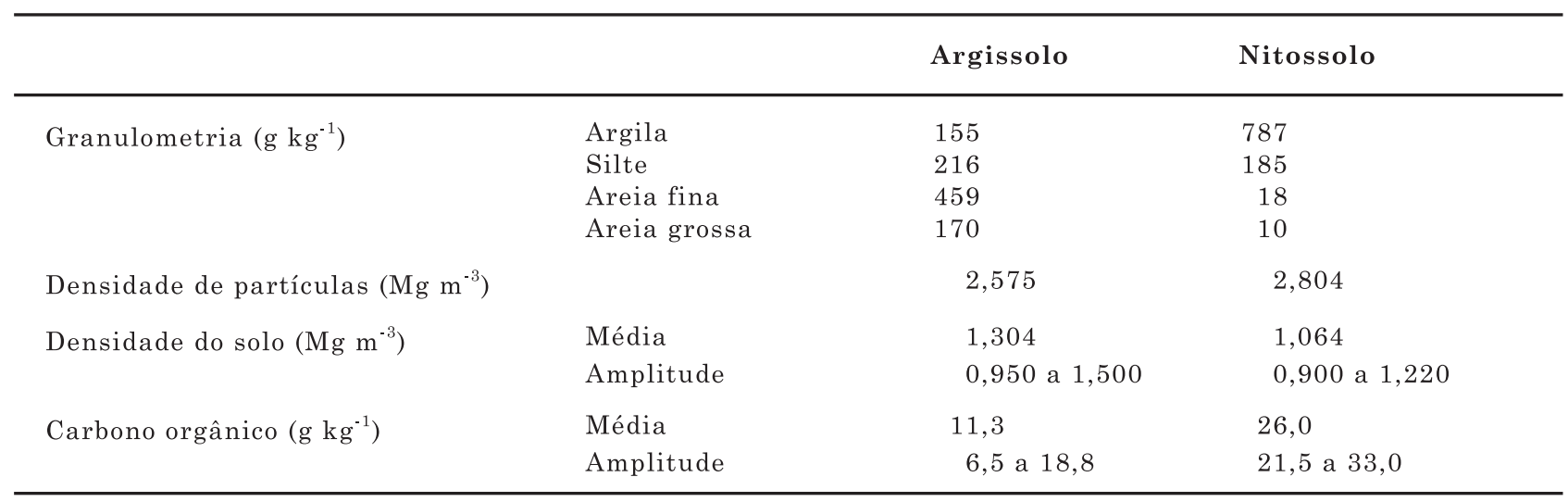


em uma prensa de compressão uniaxial, no Laboratório de Física do Solo da Universidade Federal de Santa Maria (UFSM). O carregamento na prensa de compressão uniaxial foi feito em três etapas, como descrito a seguir. Primeiramente, fez-se o carregamento das cargas de 12,5, 25, 50, 100, $200 \mathrm{e}$ $400 \mathrm{kPa}$, admitindo-se que esta última carga fosse maior que a pressão de pré-consolidação das amostras em estudo. Em segundo lugar, efetuou-se o descarregamento seqüencial de todas as cargas aplicadas. Por fim, terminado o descarregamento, aplicaram-se novamente todas as cargas, incluindo as de 800 e $1.600 \mathrm{kPa}$. Tanto nos carregamentos como nos descarregamentos, as leituras no extensômetro foram feitas após cinco minutos de aplicação da carga. Neste trabalho, a elasticidade é expressa pelo coeficiente de descompressão $(\mathrm{Cd})$, que corresponde à declividade da reta de descarregamento/ recarregamento (Figura 1), e pelo índice de recuperação (Ir), calculado por meio da seguinte equação:

$$
\mathrm{I}_{\mathrm{r}}=100 \frac{\Delta \mathrm{e}_{\mathrm{d}}}{\Delta \mathrm{e}_{\mathrm{c}}}
$$

em que $I r=$ índice de recuperação $(\%) ; \Delta e_{d}=$ variação do índice de vazios durante o descarregamento; e $\Delta e_{c}$ = variação do índice de vazios durante o carregamento.

Por fim, a elasticidade foi expressa por meio dos valores absolutos observados para o decréscimo da densidade do solo, objetivando avaliar a magnitude da recuperação no volume do solo.

$\mathrm{O}$ teor de $\mathrm{CO}$ foi determinado pelo método descrito por Embrapa (1997), em cada uma das amostras submetidas ao ensaio de adensamento uniaxial.

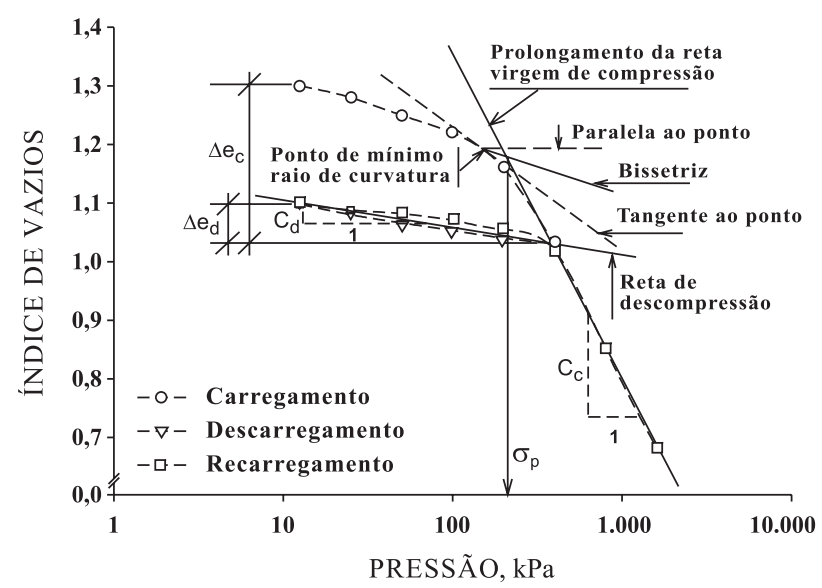

Figura 1. Curva de compressão com indicações da reta virgem, da reta de descompressão e do cálculo do índice de recuperação (Ir). $\Delta \mathbf{e}_{c}=$ variação do índice de vazios durante o carregamento; $\Delta \mathbf{e}_{\mathrm{d}}=$ variação do índice de vazios durante o descarregamento; $c_{d}=$ coeficiente de descompressão; $c_{c}=$ coeficiente de compressibilidade $; \sigma_{p}=$ pressão de pré-compressão.
A análise estatística constituiu-se na análise de variância, complementada, quando significativa, pelo teste DMS (diferença mínima significativa) a $5 \%$. Para avaliar o efeito do CO, empregou-se o estudo de correlações, fazendo-se o ajuste de equações quando conveniente. Nas figuras apresentadas, quando o ajuste das equações foi significativo, o coeficiente de determinação $\left(\mathrm{R}^{2}\right)$ das equações ajustadas é seguido de um ou dois asteriscos, respectivamente para 5 e $1 \%$ de significância.

\section{RESULTADOS E DISCUSSÃO}

A elasticidade do solo, medida pelo índice de recuperação (Ir) ou pelo coeficiente de descompressão (Cd), foi significativamente afetada pela variação da tensão de água das amostras nos dois solos estudados (Quadro 2). Para o Nitossolo, o Ir foi maior para a tensão de água de $6 \mathrm{kPa}$ em relação às demais tensões $(100,500$ e $>500 \mathrm{kPa})$, que não se diferenciaram entre si. Na tensão de água de $6 \mathrm{kPa}$, o $\mathrm{Cd}$ foi superior ao obtido com a tensão de $100 \mathrm{kPa}$, e este foi superior aos obtidos nas tensões de 500 e $>500 \mathrm{kPa}$, que não se diferenciaram. No caso do Argissolo, com relação ao Ir, as tensões de 6 e > $500 \mathrm{kPa}$ não se diferenciaram, mas foram superiores às de 100 e $500 \mathrm{kPa}$, que também não se diferenciaram. Quando se avaliou a elasticidade através do $\mathrm{Cd}$, no caso do Argissolo, ela foi maior para a tensão de $6 \mathrm{kPa}$, seguida da de $500 \mathrm{kPa}$, que foi semelhante à tensão de $100 \mathrm{kPa}$. A tensão $>500 \mathrm{kPa}$ resultou no menor $\mathrm{Cd}$, mas não se diferenciou da tensão de $100 \mathrm{kPa}$. Esses resultados corroboram as observações de O'Sullivan \& Robertson (1996) e Kirby \& O'Sullivan (1997), de que a inclinação da reta de descompressão varia com a umidade do solo.

A maior elasticidade do solo das amostras com a menor tensão de água pode ser explicada pelo fato de ela ser dependente, além da elasticidade do material que compõe o solo, do aprisionamento de bolhas de ar comprimido, que se expandem quando cessa a aplicação da carga, aumentando o volume ocupado pela mesma massa de solo, conforme observado por Perdok et al. (2002). Estudando esse fenômeno, esses autores observaram que, ao final do ensaio de compressão, cerca de $6 \%$ do volume da amostras ainda era ocupado por ar.

Quanto mais seco estiver o solo, mais facilmente o ar é expulso dos poros durante a sua compressão. Nas amostras mais úmidas (tensão de $6 \mathrm{kPa}$ ), a maior quantidade de água dificulta a expulsão do ar dos poros do solo, aumentando o confinamento de bolhas de ar, resultando em aumento da elasticidade do solo. Esse efeito é mais pronunciado quando o intervalo entre a aplicação e o descarregamento das cargas é curto, como no caso deste estudo, ou, mais ainda, como nas condições de campo, durante a passagem de uma 
Quadro 2. Carbono orgânico (CO), densidade do solo (Ds), umidade gravimétrica (Ug), índice de vazios (e), grau de saturação com água (Gs), índice de recuperação (Ir) e coeficiente de descompressão (Cd) de um Nitossolo Vermelho distrófico latossólico e de um Argissolo Vermelho-Amarelo distrófico arênico, em função da tensão de água da amostra

\begin{tabular}{lccccccc}
\hline Solo/tensão & Co & Ds & Ug & e & Gs & Ir & Cd \\
\hline Nitossolo & $\mathrm{g} \mathrm{kg}^{-1}$ & $\mathrm{Mg} \mathrm{m}^{-3}$ & $\mathrm{~kg} \mathrm{~kg}^{-1}$ & & & & \\
& 22,7 & 1,044 & $0,416 \mathrm{a}^{(1)}$ & 1,697 & $69,4 \mathrm{a}$ & $16,4 \mathrm{a}$ & $0,0068 \mathrm{a}$ \\
$6 \mathrm{kPa}$ & 24,7 & 1,075 & $0,309 \mathrm{~b}$ & 1,621 & $54,3 \mathrm{~b}$ & $11,4 \mathrm{~b}$ & $0,0038 \mathrm{~b}$ \\
$100 \mathrm{kPa}$ & 24,9 & 1,050 & $0,286 \mathrm{c}$ & 1,678 & $48,1 \mathrm{c}$ & $11,8 \mathrm{~b}$ & $0,0029 \mathrm{c}$ \\
$500 \mathrm{kPa}$ & 24,4 & 1,089 & $0,274 \mathrm{c}$ & 1,587 & $49,1 \mathrm{c}$ & $12,3 \mathrm{~b}$ & $0,0030 \mathrm{c}$ \\
$>500 \mathrm{kPa}$ & & & & & & & \\
Argissolo & $14,5 \mathrm{~A}$ & 1,311 & $0,240 \mathrm{~A}$ & 0,976 & $65,0 \mathrm{~A}$ & $23,4 \mathrm{~A}$ & $0,0056 \mathrm{~A}$ \\
$6 \mathrm{kPa}$ & $10,6 \mathrm{~B}$ & 1,312 & $0,136 \mathrm{~B}$ & 0,977 & $36,6 \mathrm{~B}$ & $14,0 \mathrm{~B}$ & $0,0027 \mathrm{BC}$ \\
$100 \mathrm{kPa}$ & $15,4 \mathrm{~A}$ & 1,276 & $0,105 \mathrm{C}$ & 1,052 & $25,8 \mathrm{C}$ & $16,0 \mathrm{~B}$ & $0,0032 \mathrm{~B}$ \\
$500 \mathrm{kPa}$ & $13,3 \mathrm{AB}$ & 1,318 & $0,014 \mathrm{D}$ & 0,980 & $3,7 \mathrm{D}$ & $20,6 \mathrm{~A}$ & $0,0017 \mathrm{C}$ \\
$>500 \mathrm{kPa}$ & & & & & & & \\
\hline
\end{tabular}

(1) Médias seguidas pela mesma letra na coluna, para cada solo separadamente, não diferem estatisticamente pelo teste DMS a $5 \%$ (a ausência de letras indica variáveis que não apresentaram variação significativa entre as tensões de água).

máquina ou animal sobre o solo, em que o tempo de permanência da carga aplicada, em geral, é de apenas frações de segundo.

Para o Argissolo, o índice de recuperação foi semelhante na maior e na menor tensão de água, o mesmo não ocorrendo para o coeficiente de descompressão. Provavelmente, os altos valores de Ir observados nas amostras mais secas sejam devidos à menor deformação que essas amostras sofreram, e, assim, mesmo uma pequena expansão após a remoção da carga resultou em valores percentuais elevados. Para o Nitossolo, esse comportamento não foi observado, provavelmente porque não se obtiveram valores tão baixos de umidade, quando comparado ao Argissolo.

Com base nessas observações, realizou-se um estudo de correlação entre os índices de elasticidade do solo e o grau de saturação deste, dividindo-se as amostras em duas classes de densidade do solo, determinada no teste anterior. As relações matemáticas obtidas, para o Argissolo e o Nitossolo, são mostradas na figura 2.

As curvas mostradas (Figura 2) confirmam que a elasticidade aumenta quando o solo se torna mais úmido, porque, como dito anteriormente, provavelmente nessa situação aumenta o aprisionamento de bolhas de ar no interior do solo. Quando se compararam as classes de densidade, para os dois solos, percebe-se que o solo mais denso tem maior recuperação percentual do volume após cessar a aplicação da carga, mas que isso não é reflexo de maior coeficiente de descompressão. A razão para isso é que nas amostras mais densas a deformação é menor e, assim, mesmo uma pequena recuperação de volume resulta em valor percentual elevado. Para confirmar essa suposição, avaliou-se a relação entre os valores absolutos do decréscimo da densidade do solo, após a remoção da carga aplicada, e seu grau de saturação com água. Observou-se que, no solo mais denso, a redução da densidade após remoção da carga é menor do que no solo menos denso (Figura 3), confirmando a suposição de que o maior percentual de recuperação é decorrente da menor deformação durante o carregamento, e não de uma maior recuperação após o descarregamento.

Para o Nitossolo (Figura 4a,b), o incremento de $\mathrm{CO}$ resultou em aumento significativo da elasticidade do solo em todas as tensões de água, com exceção para o Cd na tensão $>500 \mathrm{kPa}$. Para o Argissolo (Figura 4c,d), o incremento de $\mathrm{CO}$ resultou em aumento do Ir somente nas amostras mais úmidas (com menores tensões de água), enquanto nas demais houve decréscimo do Ir, mas em nenhum caso se observou correlação significativa. O coeficiente de descompressão aumentou significativamente em todas as tensões de água à medida que aumentava o teor de CO. Provavelmente isso aconteceu porque, no Argissolo, o aumento do teor de CO foi acompanhado de diminuição da densidade, o que resultou, nas amostras mais ricas em CO, em maior deformação. Assim, mesmo que o $\mathrm{Cd}$ dessas amostras tenha aumentado, a recuperação percentual do volume não foi tão grande quanto em amostras que deformaram menos. Novamente essa suposição foi confirmada quando se avaliaram os valores absolutos da redução da densidade após a remoção das cargas (Figura 5). A variação da densidade após a remoção das cargas cresceu linearmente com o aumento do teor de CO do 
(a)

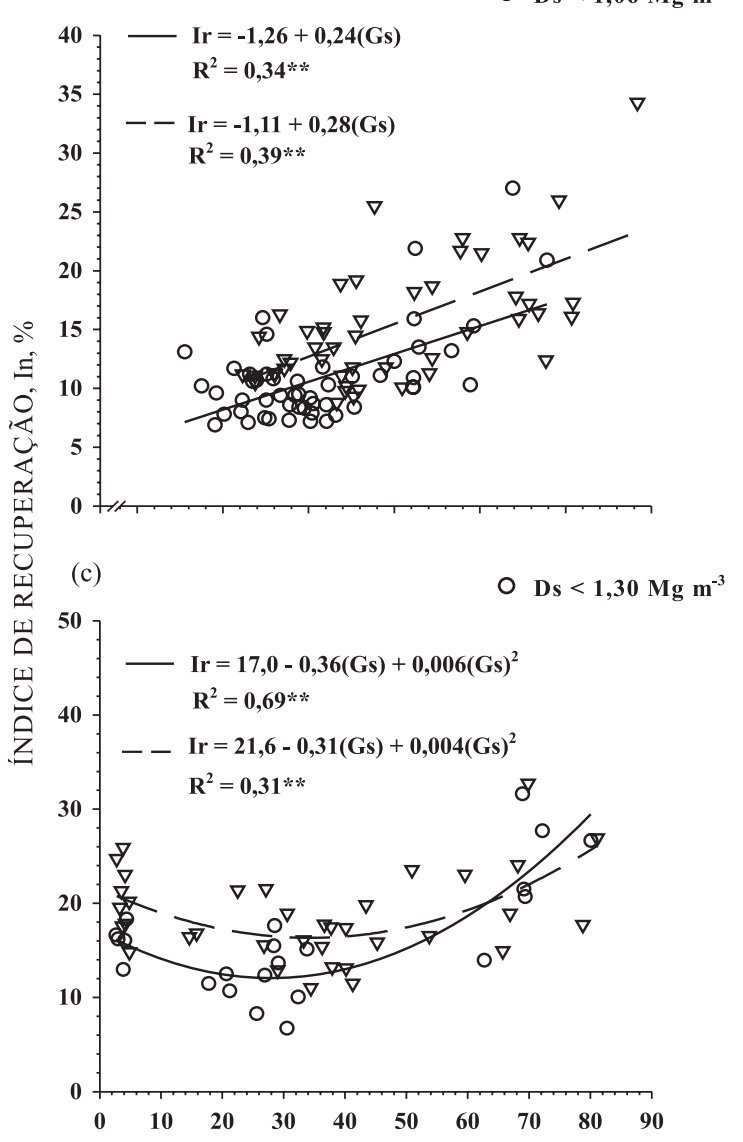

(b) $\nabla \mathrm{Ds}>1,06 \mathrm{Mg} \mathrm{m}^{-3}$

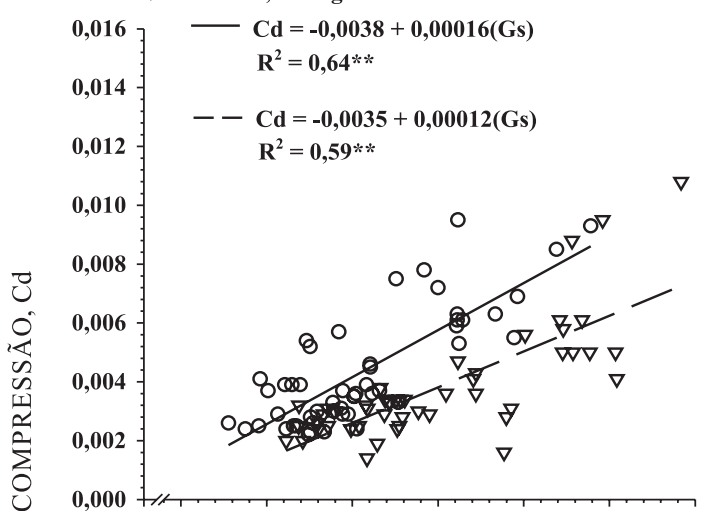

(d) $\nabla \quad$ Ds $>1,30 \mathrm{Mg} \mathrm{m}^{-3}$

$0,016]-\mathrm{Cd}=0,0022+0,00007(\mathrm{Gs})$ $\mathbf{R}^{2}=\mathbf{0 , 4 9 * *}$

- $\mathrm{Cd}=0,0010+0,00004(\mathrm{Gs})$ $0,010-R^{2}=0,62^{* *} \quad \circ$ $0,010=0$

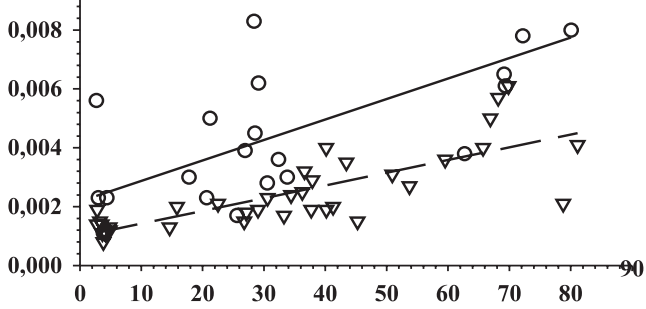

GRAU DE SATURAÇÃO, Gs, \%

Figura 2. Índice de recuperação e coeficiente de descompressão de um Nitossolo Vermelho distrófico latossólico (a) e (b), respectivamente) e de um Argissolo Vermelho-Amarelo distrófico arênico (c) e (d), respectivamente), em função da densidade e do grau de saturação com água do solo.
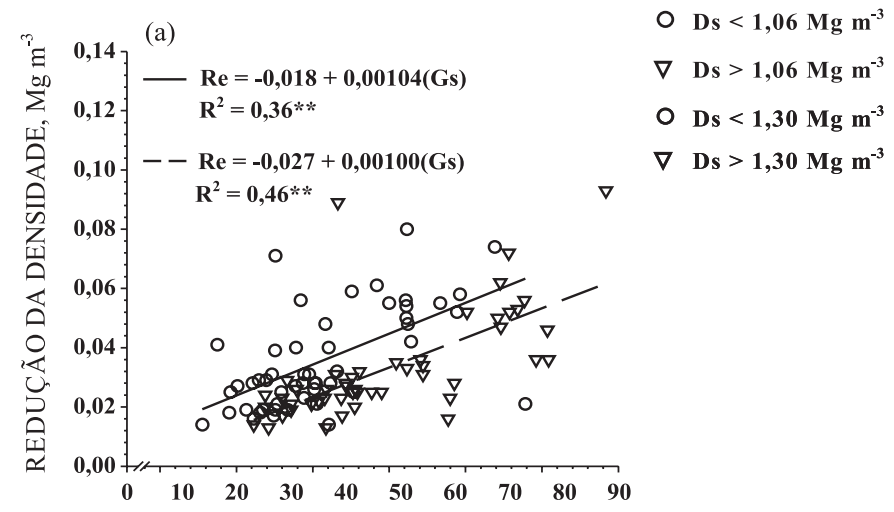

(b)

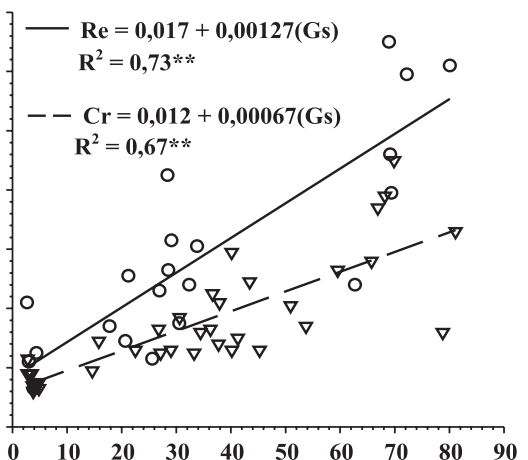

GRAU DE SATURAÇ̃̃O, Gs, \%

Figura 3. Redução da densidade do solo (Rebound) após o descarregamento, em função do grau de saturação com água de um Nitossolo Vermelho distrófico latossólico (a) e de um Argissolo Vermelho-Amarelo distrófico arênico (b), para duas classes de densidade.

solo em todas as tensões, para os dois solos estudados. No quadro 3 são apresentados, para cada tensão e solo, os valores dos parâmetros da equação linear ajustada aos dados observados, conforme o modelo: 

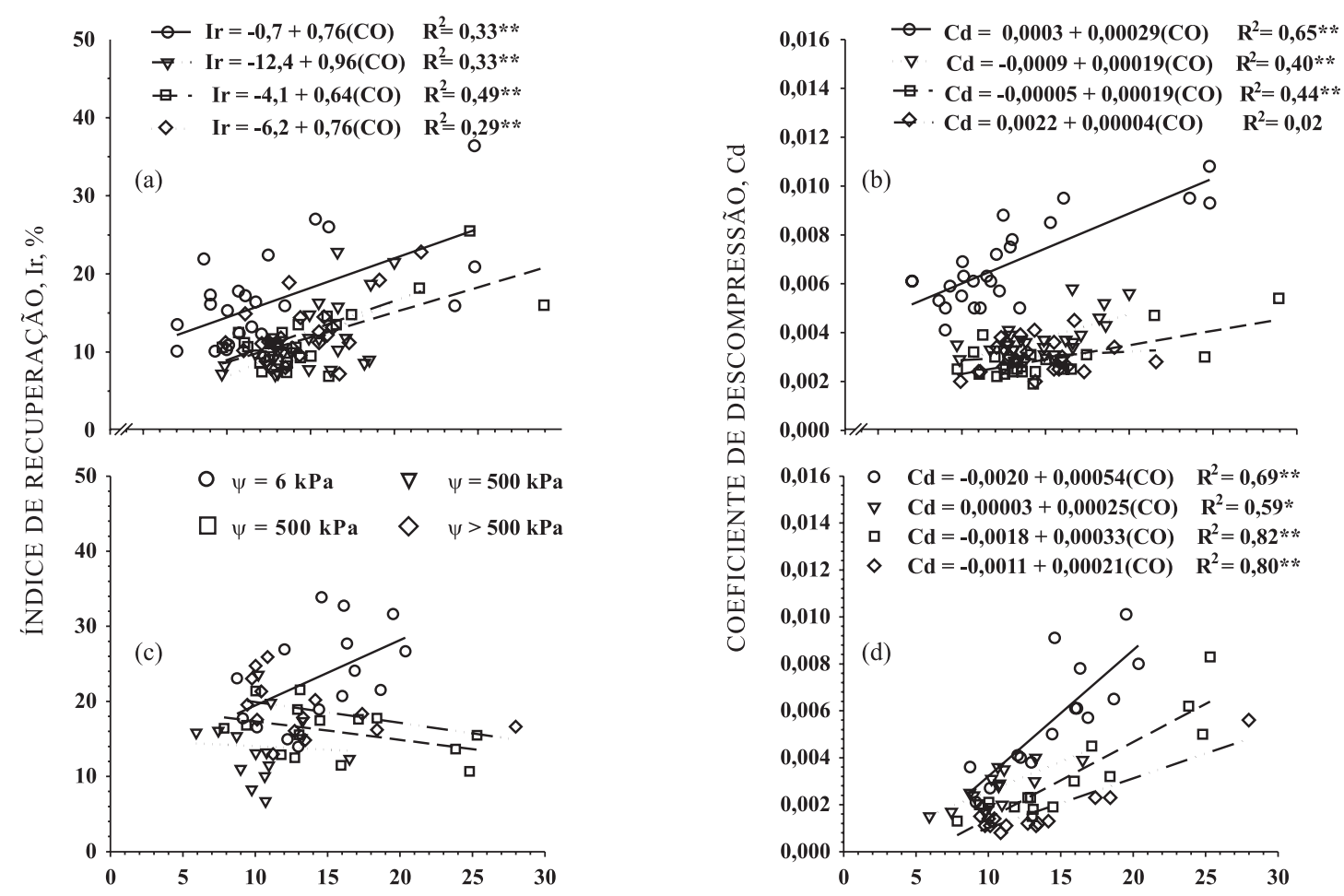

CARBONO ORGÂNICO, CO, $\mathrm{g} \mathrm{kg}^{-1}$

Figura 4. Índice de recuperação e coeficiente de descompressão em função do teor de carbono orgânico de um Nitossolo Vermelho distrófico latossólico (a) e (b), respectivamente, e de um Argissolo VermelhoAmarelo distrófico arênico (c) e (d), respectivamente, submetidos a quatro tensões de água ( $\psi)$.

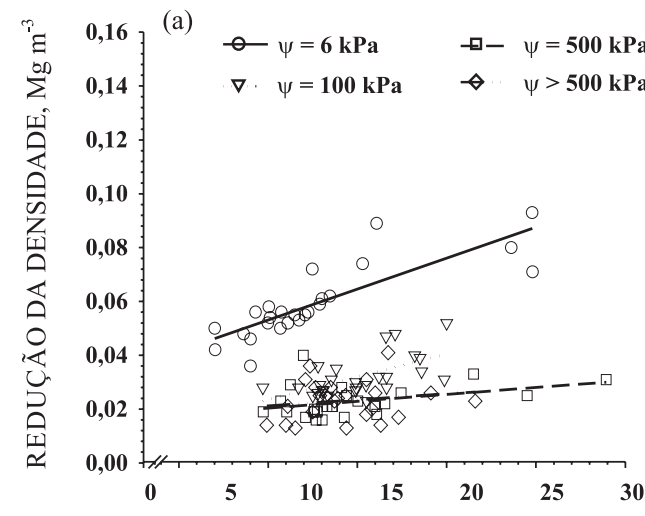

(b)

CARBONO ORGÂNICO, $\mathrm{g} \mathrm{kg}^{-1}$

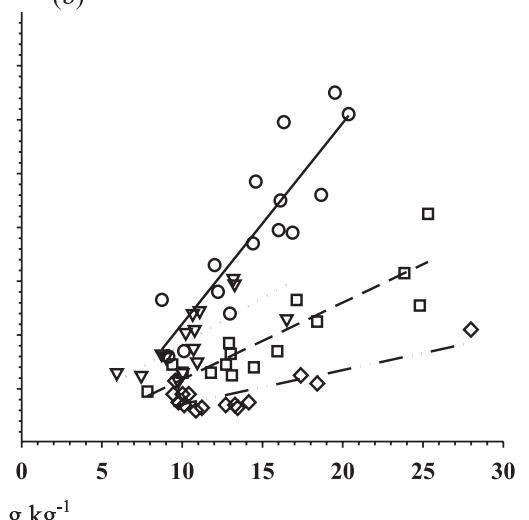

Figura 5. Redução da densidade após o descarregamento do solo em função do teor de carbono orgânico para um Nitossolo Vermelho distrófico latossólico (a) e para um Argissolo Vermelho-Amarelo distrófico arênico (b), submetidos a quatro tensões de água $(\psi)$.

$$
\operatorname{Re}=a+b(\mathrm{CO})
$$

em que $\mathrm{Re}=$ redução da densidade após remoção da carga aplicada $\left(\mathrm{Mg} \mathrm{m}^{-3}\right)$; a e $b=$ parâmetros de ajuste $\left(\mathrm{Mg} \mathrm{m}^{-3} \mathrm{e} \mathrm{Mg} \mathrm{m}^{-3} \%^{-1}\right.$, respectivamente); e $\mathrm{CO}=$ teor de carbono orgânico ( \%).

O acúmulo de matéria orgânica geralmente está associado a aumento da água retida em uma mesma tensão (Scheinost et al., 1997; Carvalho et al., 1997;
Tormasella et al., 2000). Assim, o aumento da elasticidade associado ao aumento do teor de CO do solo, observados neste trabalho, é explicado pela elasticidade da própria MOS, que é mais elástica que as partículas minerais (Soane, 1990), e pelo aumento da probabilidade do confinamento de bolhas de ar, uma vez que há aumento da água retida no solo. Dessa forma, o aumento da elasticidade produzido pela grande elasticidade do material orgânico é 
Quadro 3. Valores médios do teor de carbono orgânico (CO) e da redução da densidade (Re) e valores dos parâmetros e do coeficiente de determinação da equação $\operatorname{Re}=a+b(C O)$ em função da tensão de água no solo, para amostras de um Nitossolo Vermelho distrófico latossólico e de um Argissolo Vermelho-Amarelo distrófico arênico

\begin{tabular}{|c|c|c|c|c|c|}
\hline Solo/tensão & $\mathrm{CO}$ & Re & A & $\mathbf{b}$ & $\mathbf{R}^{2}$ \\
\hline Nitossolo & $\mathrm{g} \mathrm{kg}^{-1}$ & $\mathrm{Mg} \mathrm{m}^{-3}$ & & & \\
\hline $6 \mathrm{kPa}$ & 22,7 & $0,059 \mathrm{a}^{(1)}$ & $-0,007$ & 0,0023 & $0,68^{* *(2)}$ \\
\hline $100 \mathrm{kPa}$ & 24,7 & $0,032 \mathrm{~b}$ & $-0,011$ & 0,0017 & $0,38^{*}$ \\
\hline $500 \mathrm{kPa}$ & 24,9 & $0,023 \mathrm{c}$ & 0,010 & 0,0005 & 0,15 \\
\hline$>500 \mathrm{kPa}$ & 24,4 & $0,023 \mathrm{c}$ & 0,012 & 0,0004 & 0,03 \\
\hline \multicolumn{6}{|l|}{ Argissolo } \\
\hline $6 \mathrm{kPa}$ & 14,5 & $0,078 \mathrm{~A}$ & $-0,030$ & 0,0075 & $0,78^{* *}$ \\
\hline $100 \mathrm{kPa}$ & 10,6 & $0,038 \mathrm{~B}$ & $-0,002$ & 0,0034 & $0,49 * *$ \\
\hline $500 \mathrm{kPa}$ & 15,4 & $0,039 \mathrm{~B}$ & $-0,005$ & 0,0028 & $0,80^{* *}$ \\
\hline$>500 \mathrm{kPa}$ & 13,3 & $0,018 \mathrm{C}$ & $-0,002$ & 0,0013 & $0,67 * *$ \\
\hline
\end{tabular}

${ }^{(1)}$ Médias seguidas de letras iguais não diferem estatisticamente pelo teste DMS a $5 \%$. ${ }^{(2)}$ Um e dois asteriscos indicam que as equações ajustadas são significativas, respectivamente, a 5 e $1 \%$.

potencializado pela maior probabilidade de aprisionamento de bolhas de ar dentro da amostra enriquecida por esses materiais.

De maneira geral, a redução da densidade do solo após remoção das cargas aplicadas foi sensivelmente afetada pela umidade do solo, assim como pela variação do teor de $\mathrm{CO}$ e pela densidade. Contudo, os valores médios observados foram inferiores a $0,08 \mathrm{Mg} \mathrm{m}^{-3}$, corroborando as observações de Stone \& Larson (1980) e McBride \& Watson (1990), que constataram reduções inferiores a 0,05 e $0,08 \mathrm{Mg} \mathrm{m}^{-3}$, respectivamente. Para os primeiros autores esses valores são insignificantes, podendo ser desconsiderados em modelos matemáticos para previsão da compactação do solo.

Entretanto, os resultados apresentados foram obtidos com aplicações de cargas estáticas por tempo relativamente longo (cinco minutos), especialmente quando comparado com o tempo de aplicação de cargas resultantes da passagem de uma máquina ou animal sobre o solo (frações de segundos). É possível que, nas condições que ocorrem no campo, o incremento na elasticidade, aqui relatado, seja suficiente para justificar maior resistência à compactação observada em alguns trabalhos com o sistema de semeadura direta. Isso está em consonância com a observação de Perdok et al. (2002), para quem o aprisionamento de bolhas de ar dependerá da intensidade e do tempo de aplicação da carga, do teor de água do solo e do espaço poroso. Assim, em campo, em razão do pouco tempo de carregamento, é provável que o aprisionamento de bolhas de ar seja maior, gerando elasticidade maior.

Os valores do índice de recompressão Cr e razão de recompressão Cre dependem do valor da tensão (ou carga) no qual o ciclo de descarregamento e recarregamento começa, particularmente se antes ou depois da tensão de pré-consolidação $\left(\sigma_{\mathrm{p}}\right)($ Holtz \& Kovacs, 1981). Assim, admitindo-se que o Cd e Ir também terão essa influência (Perdock et al., 2002), e con- siderando que os dados aqui apresentados foram obtidos com o ciclo de descarregamento e recarregamento iniciado após a aplicação de cargas superiores a $\sigma_{p}$, é possível que no campo, com a aplicação de cargas menores que a $\sigma_{\mathrm{p}}$, se observem efeitos maiores da elasticidade do solo que constatada.

\section{CONCLUSÕES}

1. A elasticidade do solo é afetada pela variação da sua umidade, assim como pelo teor de carbono orgânico (CO) e pela densidade.

2. Aumentos no teor de $\mathrm{CO}$ resultam em aumento da elasticidade do solo.

3. Nas condições deste estudo, a redução da densidade do solo, após remoção da carga, em média é inferior a $0,08 \mathrm{Mg} \mathrm{m}^{-3}$.

\section{AGRADECIMENTOS}

Nossos agradecimentos aos colegas Milton da Veiga e Carla Maria Pandolfo, pesquisadores da Empresa de Pesquisa Agropecuária e Extensão Rural de Santa Catarina - EPAGRI, e Celso Aita e Sandro José Giacomini, professores do Departamento de Solos da Universidade Federal de Santa Maria, que cederam seus experimentos para a coleta das amostras de solos utilizadas neste estudo.

\section{LITERATURA CITADA}

AITA, C.; PORT, O. \& GIACOMINI, S.J. Dinâmica do nitrogênio no solo e produção de fitomassa por plantas de cobertura no outono/inverno com o uso de dejetos de suínos. R. Bras. Ci. Solo, 30:901-910, 2006. 
BAVER, L.D.; GARDNER, W.H. \& GARDNER, W.R. Soil physics. 4.ed. New York, John Wiley \& Sons, 1972. 498p.

BRAIDA, J.A.; REICHERT, J.M.; VEIGA, M. \& REINERT, D.J. Resíduos vegetais na superfície e carbono orgânico do solo e suas relações com a densidade máxima obtida no ensaio Proctor. R. Bras. Ci. Solo, 30:605-614, 2006.

CARVALHO, E.J.M.; FIGUEIREDO, M.S. \& COSTA, L.M. Comportamento físico-hídrico de um Podzólico VermelhoAmarelo câmbico fase terraço sob diferentes sistemas de manejo. Pesq. Agropec. Bras., 34:257-265, 1999.

EMPRESA BRASILEIRA DE PESQUISA AGRPECUÁRIA . EMBRAPA. Centro Nacional de Pesquisa de Solos. Manual de métodos de análise de solos. 2.ed. Rio de Janeiro, 1997. $212 p$.

HILLEL, D. Soil dynamics: Stress, strain and strength. In: HILLEL, D., ed. Environmental soil physics. New York, Academic Press, 1998. p.341-382.

HOLTZ, R.D. \& KOVACS, W.D. An introduction to geotechnical engineering. New Jersey, Prentice-Hall, 1981. 733p.

KIRBY, J.M. \& O'SULLIVAN, M.F. Critical state soil mechanics analysis of the constant cell volume triaxial test. Eur. J. Soil Sci., 48:71-78, 1997.

MCBRIDE, R.A. \& WATSON, G.C. An investigation of the reexpansion of unsaturated, structured soils during cyclic static loading. Soil Till. Res., 17:241-253, 1990.

O'SUllivan, M.F. \& ROBERTSON, E.A.G. Critical state parameters from intact samples of two agricultural topsoils. Soil Till. Res., 39:161-173, 1996.
PERDOK, U.D.; KROESBERGEN, B. \& HOOGMOED, W.B. Possibilities for modeling the effect of compression on mechanical and physical properties of various Dutch soil types. Soil Till. Res., 65:61-75, 2002.

SCHEINOST, A.C.; SINOWSKI, W. \& AUERSWALD, K. Rationalization of soil water retention curves in a highly variable soils cape, I. Developing a new pedotransfer function. Geoderma, 78:129-143, 1997.

SILVA, A.J.N. \& CABEDA, M.S.V. Compressibilidade de um Argissolo Amarelo de tabuleiro costeiro submetido a pressões uniaxiais. In.: CONGRESSO BRASILEIRO DE CIÊNCIA DO SOLO, 30., Recife, 2005. Anais. Viçosa, MG, Sociedade Brasileira de Ciência do Solo, 2005. CD-ROOM.

SILVA, V.R.; REINERT, D.J. \& REICHERT, J.M. Densidade do solo, atributos químicos e sistema radicular do milho afetados pelo pastejo e manejo do solo. R. Bras. Ci. Solo, 24:191-199, 2000

SOANE, B.D. The role of organic matter in soil compactability: A review of some practical aspects. Soil Till. Res., 16:179$201,1990$.

STONE, J.A. \& LARSON, W.E. Rebound of five one dimensionally compressed unsaturated granular soils. Soil Sci. Soc. Am. J., 44:819-822, 1980.

TORMASELLA, J.; HODNETT, M. \& ROSSATO, L. Pedotransfer functions for the estimation of soil water retention in Brazilian soils. Soil Sci. Soc. Am. J., 64:327338, 2000.

VEIGA, M.; HORN, R.; REINERT, D.J. \& REICHERT, J.M. Soil compressibility and penetrability of an Oxisol from Southern Brazil, as affected by long-term tillage systems. Soil Till. Res., 92:104-113, 2007. 